\title{
Review and Evaluate the Material for Prospective Programmers
}

\author{
Danang Kurniawan \\ 195120031 \\ Fakultas Komputer \\ danang.student@umitra.ac.id
}

\begin{abstract}
Struktur data merupakan sesuatu yang berfungsi untuk mengorganisasikan data sedemikian rupa sehingga implementasi ( penerapan ) atau pemeliharaan logika program menjadi lebih terstruktur. Secara umum program adalah kumpulan intruksi atau perintah yang disusun sedemikian rupa sehingga mempunyai urutan logika yang tepat untuk menyelesaikan suatu persoalan.

Turbo pascal merupakan salah satu aplikasi program. Selanjutnya adalah algoritma yang merupakan jantung semua program yang merupakan urutan langkah sistematis dan dirancang untuk menyelesaikan suatu masalah spesifik dan dengan usaha yang paling minimal.
\end{abstract}

Kata Kunci : Struktur data dan Algoritma 


\section{A. PENDAHULUAN}

Materi Kuliah Section 01 Membahas Tentang Pengertian Struktur Data selanjutnya membahas mengenai Pengertian Algoritma, karakteristik algoritma yang terdiri dari:

1. Input

2. Output

3. Definite (Jelas)

4. Efektive

5. Terminate (berakhir)

Struktur data merupakan sesuatu yang berfungsi untuk mengorganisasikan data sedemikian rupa sehingga implementasi ( penerapan ) atau pemeliharaan logika program menjadi lebih terstruktur. Secara umum program adalah kumpulan intruksi atau perintah yang disusun sedemikian rupa sehingga mempunyai urutan logika yang tepat untuk menyelesaikan suatu persoalan.

Program aplikasi

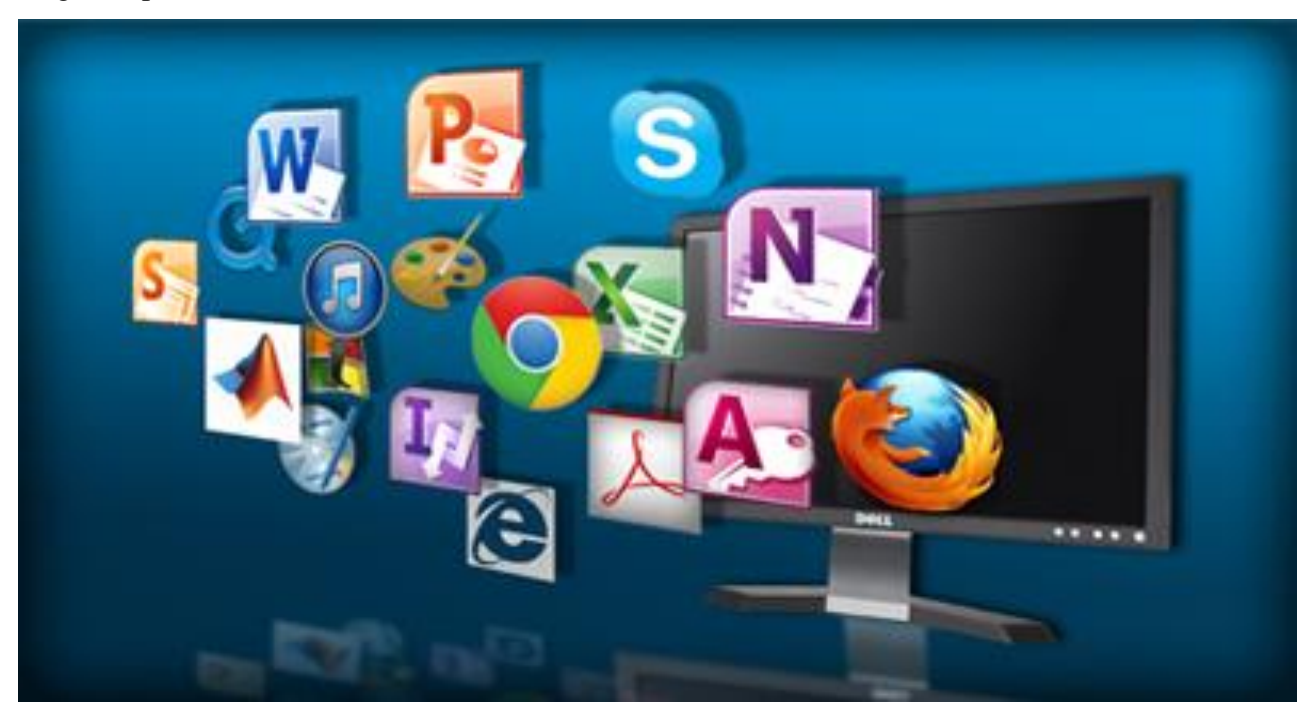

Didalam ilmu komputer, pemahaman tentang struktur data yang berkembang selama ini yaitu cara menyimpan, mengatur, dan mengelola 
data dalam media penyimpanan komputer sehingga data dapat digunakan secara efisien. Bahasa Program merupakan suatu himpunan dari aturan sintaks dan semantik yang dipakai untuk mendefinisikan program komputer. Bahasa ini memungkinkan seorang programmer dapat menentukan secara persis data mana yang akan diolah oleh komputer, bagaimana data ini akan disimpan/diteruskan, dan jenis langkah apa yang akan diambil dalam berbagai situasi secara persis. Beralih ke Type data, maksud dari tipe data adalah himpunan yang bisa kita temui pada semua data. Dengan memahami suatu tipe data, kita jadi bisa menentukan suatu nilai data yang dimiliki dari data tersebut. Salah satu dari bentuk penerapan tipe data yang ada dalam kehidupan sehari-hari adalah bilangan bulat. Maka sebenarnya penulisan suatu bilangan pada data bermacam-macam jenisnya, seperti $1 / 2$ atau 3,5. Bilangan ini termasuk bilangan yang tidak bulat, contoh dari bilangan bulat adalah 3, 1, 2, 5 dan masih banyak lagi.

Lebih konkret nya lagi sebuah tipe data akan sangat sering ditemui dalam dunia pemrograman komputer. Dalam tahap awal pembuatan sebuah program, kalian terlebih dahulu harus menentukan tiba data yang digunakan. Kebanyakan tipe data yang digunakan oleh para programmer adalah real, integer, double, char, string dan masih banyak tipe data yang lain.

Setelah seorang programmer menentukan tipe data yang akan digunakan tersebut mereka akan langsung mendeklarasikan di awal tahap pembuatan program tersebut. Hal ini digunakan untuk memberi kategori atau batasan khusus pada data yang digunakan dalam sebuah program tersebut. Penentuan dari memori juga dapat dipilih ketika tipe data tersebut sudah ditentukan. 


\section{B. PEMBAHASAN / STUDI KASUS}

\section{Struktur Data}

Didalam ilmu komputer, pemahaman tentang struktur data yang berkembang selama ini yaitu cara menyimpan, mengatur, dan mengelola data dalam media penyimpanan komputer sehingga data dapat digunakan secara efisien. Setiap baris kumpulan kolom disebut catatan. Lebar kolom untuk data dapat berubah dan bervariasi. Ada kolom yang lebarnya berubah secara dinamis sesuai dengan input pengguna dan ada juga kolom yang lebarnya diperbaiki.

Sesuai sifatnya, struktur data dapat diterapkan untuk pemrosesan basis data, misalnya untuk tujuan data keuangan, atau untuk pengolah kata. Strutur data ini kolomnya berubah-ubah secara dinamis. Contoh struktur data dapat dilihat dalam spreadsheet, database, pengolah kata, gambar terkompresi, dan mengompresi file dengan teknik tertentu yang memanfaatkan struktur data. Kemudian jika kita menganalogikan pemahaman algoritma ini ke tingkat yang lebih spesifik, maka algoritma dapat diartikan sebagai kumpulan langkah-langkah. Algoritma di dunia nyata dapat mencakup bahasa apa pun.

Dalam pemrograman komputer, hal yang paling penting untuk dipahami adalah bagaimana logika kita dalam memproses pola pikir untuk menemukan solusi, inovasi, dan bahkan untuk menyelesaikan masalah pemrograman yang akan dibuat itu secara berurutan.

2. Bahasa Program

Bahasa Program merupakan suatu himpunan dari aturan sintaks dan semantik yang dipakai untuk mendefinisikan program komputer. Bahasa ini memungkinkan seorang programmer dapat menentukan secara persis data mana yang akan diolah oleh komputer, 


\section{Section 01}

bagaimana data ini akan disimpan/diteruskan, dan jenis langkah apa yang akan diambil dalam berbagai situasi secara persis.

Fungsi dari bahasa pemrograman adalah untuk memerintahkan sebuah komputer agar bisa mengolah data sesuai dengan yang kita inginkan. Jadi, kendali sepenuhnya ada di tangan kita. Keluaran dari bahasa pemrograman tersebut bisa berupa aplikasi ataupun program khusus, contonya seperti lampu lalu lintas. Antara lampu merah, kuning, dan hijau memiliki urutan dan jeda waktu yang berbeda, sehingga para pengendara tahu kapan harus berhenti dan kapan harus jalan.

Selain itu bahasa program bisa sebagai instruksi atau perintah yang disusun sedemikian rupa sehingga mempunyai urutan logika yang tepat untuk menyelesaikan suatu persoalan. Turbo Pascal merupakan salah satu aplikasi programnya, nah kemudian materi kuliah Struktur Data akan disampaikan mengunakan logika Turbo Pascal.

Contoh gambar program turbo pascal

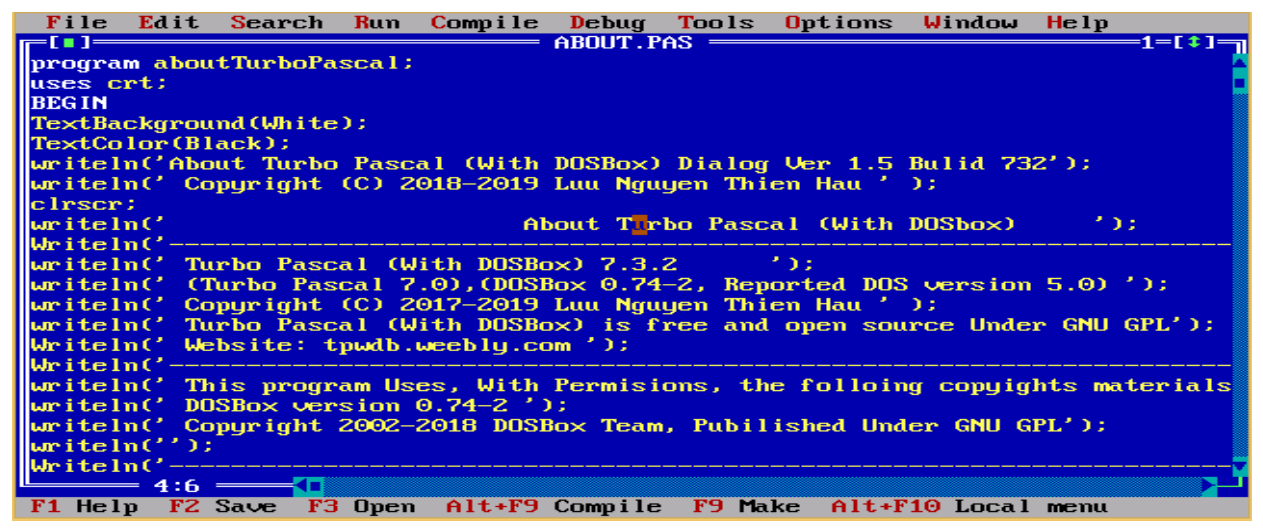

\section{Program Pascal}

Pascal adalah salah satu bahasa pemrograman komputer yang sering dipakai untuk belajar algoritma dan pemrograman bagi pemula terutama di bidang akademis salah satunya materi kuliah Struktur Data akan disampaikan menggunakan logika Turbo Pascal. 
Pascal memiliki beberapa fitur yang membuatnya cocok untuk belajar

pemrograman dan untuk membuat aplikasi komersil. Beberapa diantaranya adalah:

- Tipe data bawaan: Pascal memiliki tipe data standar yang umum terdapat dalam bahasa pemrograman komputer seperti Integer, Real, Character, dan Boolean.

- Tipe data bentukan: Pascal membolehkan kita untuk membuat tipe data bentukan yang didefinisikan sendiri.

- Memiliki beragam struktur data: Pascal menyediakan beberapa struktur data seperti Array, Record, File dan Set.

- Aturan tipe data yang ketat: Pascal membatasi penggunaan tipe data secara ketat. Kita hanya bisa menggunakan variabel untuk 1 tipe data saja dan variabel tersebut harus dideklarasikan terlebih dahulu.

- Mendukung struktural programming: Bahasa Pascal dirancang dengan konsep pemrograman terstruktur yang mendukung sub program melalui fungsi dan prosedur

- Sederhana dan expresif: Pascal banyak menggunakan perintah-perintah dalam bahasa inggris sederhana, sehingga mudah dipahami.

- Mendukung pemrograman objek: Walaupun tidak banyak dibahas, tetapi Pascal juga mendukung pemrograman berbasis objek, terutama pada compiler versi terakhir.

Bahasa Pascal menerapkan konsep procedural dan structured programming yang baik, sehingga pas untuk belajar konsep programming. Perintah Pascal mirip dengan bahasa inggris sehari-hari seperti begin, end, write, dan read 


\section{Struktur Program Pascal:}

1. Judul Program

2. Blok Program

a. Deklarasi Unit Pascal

b. Bagian Deklarasi

- Deklarasi Variabel

- Deklarasi Konstanta

- Deklarasi Label

- Deklarasi Tipe Data

- Deklarasi Prosedur

- Deklarasi Fungsi

c. Bagian Program

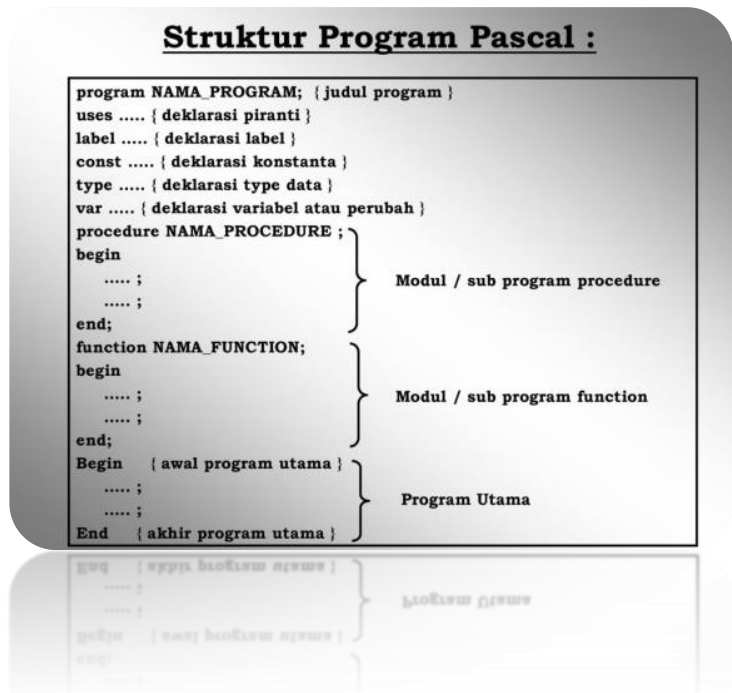

4. Langkah-langkah Pembuatan Program

1. Mendefinisikan permasalahan

Di tahapan ini kita harus mengerti dengan baik mengenai permasalahan yang ingin diselesaikan.

2. Membuat rumusan untuk pemecahan masalah 
Disini kita dapat membuat rumusan algoritma untuk pemecahan masalah tersebut. Dapat disusun dalam bentuk pseudocode maupun flowchart.

3. Implementasi dan Coding

Ditahapan ini kita melibatkan bahasa pemrograman, dengan menentukan bahasa program apa yang akan dipilih.

4. Testing ( Menguji Coba) dan Membuat Dokumentasi

Ditahapan ini adalah tahapan pengujian terhadap program dengan tujuan untuk mengetahui apakah telah tepat memberi solusi dari permasalahan yang sebelumnya muncul.

Jenis-Jenis Type Data :

1. Type sederhana (simple type)

- Tipe Ordinal ( untuk semua bilangan kecuali bilangan real )

$>$ Integer $[-32768 \ldots 32767] 2$ bytes

Shortint $[-128 \ldots 127] 1$ byte

$>$ Longint $[-2147483648 \ldots 2147483647] 4$ bytes

$>$ Boolean [benar...salah] 1 byte

$>$ Char [ untuk karakter 1 huruf ] 'A' 1 byte

$>$ Byte $[0 \ldots 255] 1$ byte

- Tipe real ( untuk bilangan Desimal ) 6 bytes

2. Type String (data yang berisi sederetan karakter ) 'INFORMASI'

3. Type terstruktur ( structured type ) untuk ukuran tempat

- Larik ( Array )

- Rekaman (record)

- Himpunan (set)

- Berkas ( file )

4. Type Pointer ( Dijelaskan Dalam Bab SENARAI BERANTAI )

\section{Contoh Type Array}

VAR nilai : ARRAY [ 1..maks_mhs ] of char 


\section{Contoh Type RECORD}

TYPE rec_mhs $=$ record

Nim : string ( 10 );

Nama : string (20);

Jur : string (15);

End;

\section{ID SECURITY \\ QWTD4452377-ASP-5244166}

\section{KESIMPULAN}

Berdasarkan materi yang sudah dipaparkan di atas maka dapat di simpulkan bahwa Struktur data merupakan sesuatu yang berfungsi untuk mengorganisasikan data sedemikian rupa sehingga implementasi ( penerapan ) atau pemeliharaan logika program menjadi lebih terstruktur. Secara umum program adalah kumpulan intruksi atau perintah yang disusun sedemikian rupa sehingga mempunyai urutan logika yang tepat untuk menyelesaikan suatu persoalan.

Didalam ilmu komputer, pemahaman tentang struktur data yang berkembang selama ini yaitu cara menyimpan, mengatur, dan mengelola data dalam media penyimpanan komputer sehingga data dapat digunakan secara efisien. Bahasa Program merupakan suatu himpunan dari aturan sintaks dan semantik yang dipakai untuk mendefinisikan program komputer. Bahasa ini memungkinkan seorang programmer dapat menentukan secara persis data mana yang akan diolah oleh komputer, bagaimana data ini akan disimpan/diteruskan, dan jenis langkah apa yang akan diambil dalam berbagai situasi secara persis. Beralih ke Type data, 
maksud dari tipe data adalah himpunan yang bisa kita temui pada semua data. Dengan memahami suatu tipe data, kita jadi bisa menentukan suatu nilai data yang dimiliki dari data tersebut. Salah satu dari bentuk penerapan tipe data yang ada dalam kehidupan sehari-hari adalah bilangan bulat. Maka sebenarnya penulisan suatu bilangan pada data bermacam-macam jenisnya, seperti $1 / 2$ atau 3,5. Bilangan ini termasuk bilangan yang tidak bulat, contoh dari bilangan bulat adalah 3, 1, 2, 5 dan masih banyak lagi.

Lebih konkret nya lagi sebuah tipe data akan sangat sering ditemui dalam dunia pemrograman komputer. Dalam tahap awal pembuatan sebuah program, kalian terlebih dahulu harus menentukan tiba data yang digunakan. Kebanyakan tipe data yang digunakan oleh para programmer adalah real, integer, double, char, string dan masih banyak tipe data yang lain.

Setelah seorang programmer menentukan tipe data yang akan digunakan tersebut mereka akan langsung mendeklarasikan di awal tahap pembuatan program tersebut. Hal ini digunakan untuk memberi kategori atau batasan khusus pada data yang digunakan dalam sebuah program tersebut. Penentuan dari memori juga dapat dipilih ketika tipe data tersebut sudah ditentukan.

\section{E. DISKUSI}

Saya bersama teman saya bernama Septian mendiskusikan tentang contoh ini dengan sangat baik Hasil diskusi dari materi ini adalah bahwa Struktur data harus dipelajari dengan baik agar pada saat membuat program lebih mudah karena manfaat struktur data untuk Merapikan data, agar data 
yang tersimpan mudah diakses, diubah, dikeluarkan, dihapus, struktur data memiliki beragam jenis tergantung kebutuhan, dan struktur data membuat program yang kita jalankan cepat dan hemat memory, struktur data ini sangat membantu kita dalam membuat algoritma atau code yang jelas, singkat dan membuat program sangat efisien. Selain itu Ada beberapa fungsi algoritma untuk memecahkan program dan pemrograman komputer.

1. Memecahkan program rumit.

2. Bisa menjadikan program yang besar menjadi program yang lebih sederhana.

3. Fungsi Algoritma juga bisa digunakan secara berulang atau lebih dari satu kali penggunaan.

4. Memudahkan dalam pembuatan program.

5. Mengatasi segala masalah dengan logika dan urut.

6. Meminimalisir penulisan program yang berulang-ulang.

7. Program yang ada menjadi lebih terstruktur dengan rapi sehingga dapat lebih mudah untuk dipahami ataupun dikembangkan.

8. Ketika terjadi kesalahan bisa dicari dengan mudah karena dengan fungsi algoritma bisa mendapatkan alur yang jelas.

9. Ketika ingin melakukan modifikasi pada program bisa dilakukan hanya pada satu modul saja tanpa harus merubah dan mengganggu modul yang lain.

Disamping itu Bahasa Pascal mempunyai ciri-ciri yaitu:

- Berurutan Susunan dari kode-kode dalam teks Pascal harus ditulis secara urut dari atas, pernyataan-pernyataan yang ditulis lebih awal akan dieksekusi lebih dahulu 
- Blok dengan batas-batas yang jelas.

- Satu pintu masuk dan satu pintu keluar pada blok pemilihan dan pengulangan.

Kemudian Suatu tipe data jika dipahami dengan baik tentunya akan bisa difungsikan dengan baik juga. Oleh karena itu untuk para programmer ataupun untuk masyarakat tentunya akan terbantu dengan memiliki pemahaman yang baik mengenai tipe data. Dengan penggunaan tipe data yang baik seorang programmer akan bisa memberi control dan batasan tersendiri pada program yang mereka buat. Dalam hal ini pada programmer bisa menentukan memori yang akan mereka gunakan. 


\section{F. REFERENCE}

[1] O. M. Febriani and A. S. Putra, "Sistem Informasi Monitoring Inventori Barang Pada Balai Riset Standardisasi Industri Bandar Lampung," J. Inform., vol. 13, no. 1, pp. 90-98, 2014.

[2] A. S. Putra, "Paperplain: Execution Fundamental Create Application With Borland Delphi 7.0 University Of Mitra Indonesia," 2018.

[3] A. S. Putra, "2018 Artikel Struktur Data, Audit Dan Jaringan Komputer," 2018.

[4] A. S. Putra, "ALIAS MANAGER USED IN DATABASE DESKTOP STUDI CASE DB DEMOS."

[5] A. S. Putra, "COMPREHENSIVE SET OF PROFESSIONAL FOR DISTRIBUTE COMPUTING."

[6] A. S. Putra, "DATA ORIENTED RECOGNITION IN BORLAND DELPHI 7.0."

[7] A. S. Putra, "EMBARCADERO DELPHI XE 2 IN GPU-POWERED FIREMONKEY APPLICATION."

[8] A. S. Putra, "HAK ATAS KEKAYAAN INTELEKTUAL DALAM DUNIA TEKNOLOGY BERBASIS REVOLUSI INDUSTRI 4.0.”

[9] A. S. Putra, "IMPLEMENTASI PERATURAN PERUNDANGAN UU. NO 31 TAHUN 2000 TENTANG DESAIN INDUSTRI BERBASIS INFORMATION TECHNOLOGY."

[10] A. S. Putra, "IMPLEMENTATION OF PARADOX DBASE."

[11] A. S. Putra, "IMPLEMENTATION OF TRADE SECRET CASE STUDY SAMSUNG MOBILE PHONE."

[12] A. S. Putra, "IMPLEMENTATION PATENT FOR APPLICATION WEB BASED CASE STUDI WWW. PUBLIKLAMPUNG. COM."

[13] A. S. Putra, "IMPLEMENTATION SYSTEM FIRST TO INVENT IN DIGITALLY INDUSTRY."

[14] A. S. Putra, "MANUAL REPORT \& INTEGRATED DEVELOPMENT ENVIRONMENT BORLAND DELPHI 7.0."

[15] A. S. Putra, "PATENT AS RELEVAN SUPPORT RESEARCH."

[16] A. S. Putra, "PATENT FOR RESEARCH STUDY CASE OF APPLE. Inc."

[17] A. S. Putra, "PATENT PROTECTION FOR APPLICATION INVENT."

[18] A. S. Putra, "QUICK REPORT IN PROPERTY PROGRAMMING."

[19] A. S. Putra, "REVIEW CIRCUIT LAYOUT COMPONENT REQUIREMENT ON ASUS NOTEBOOK."

[20] A. S. Putra, "REVIEW TRADEMARK PATENT FOR INDUSTRIAL TECHNOLOGY BASED 4.0."

[21] A. S. Putra, "TOOLBAR COMPONENT PALLETTE IN OBJECT ORIENTED PROGRAMMING."

[22] A. S. Putra, "WORKING DIRECTORY SET FOR PARADOX 7." 


\section{Section 01}

[23] A. S. Putra, "ZQUERY CONNECTION IMPLEMENTED PROGRAMMING STUDI CASE PT. BANK BCA Tbk."

[24] A. S. Putra, D. R. Aryanti, and I. Hartati, "Metode SAW (Simple Additive Weighting) sebagai Sistem Pendukung Keputusan Guru Berprestasi (Studi Kasus: SMK Global Surya)," in Prosiding Seminar Nasional Darmajaya, 2018, vol. 1, no. 1, pp. 85-97.

[25] A. S. Putra and O. M. Febriani, "Knowledge Management Online Application in PDAM Lampung Province," in Prosiding International conference on Information Technology and Business (ICITB), 2018, pp. 181-187.

[26] A. S. Putra, O. M. Febriani, and B. Bachry, "Implementasi Genetic Fuzzy System Untuk Mengidentifikasi Hasil Curian Kendaraan Bermotor Di Polda Lampung," SIMADA (Jurnal Sist. Inf. dan Manaj. Basis Data), vol. 1, no. 1, pp. 21-30, 2018.

[27] A. S. Putra, H. Sukri, and K. Zuhri, "Sistem Monitoring Realtime Jaringan Irigasi Desa (JIDES) Dengan Konsep Jaringan Sensor Nirkabel," IJEIS (Indonesian J. Electron. Instrum. Syst., vol. 8, no. 2, pp. 221-232.

[28] D. P. Sari, O. M. Febriani, and A. S. Putra, "Perancangan Sistem Informasi SDM Berprestasi pada SD Global Surya," in Prosiding Seminar Nasional Darmajaya, 2018, vol. 1, no. 1, pp. 289-294. 